\title{
Functional lesional neurosurgery for tremor: back to the future?
}

\author{
Sebastian R Schreglmann, ${ }^{1,2}$ Joachim K Krauss, ${ }^{3}$ Jin Woo Chang, ${ }^{4}$ Ernst Martin, ${ }^{5}$ \\ Beat Werner, ${ }^{5}$ Ronald Bauer, ${ }^{6}$ Stefan Hägele-Link, ${ }^{1}$ Kailash P Bhatia, ${ }^{2}$ Georg Kägi ${ }^{1}$
}

- Additional material is published online only. To view please visit the journal online (http://dx.doi.org/10.1136/ jnnp-2017-316301).

${ }^{1}$ Department of Neurology, Kantonsspital St. Gallen, St. Gallen, Switzerland

${ }^{2}$ Sobell Department of Motor Neuroscience and Movement Disorders, Institute of Neurology, UCL, London, UK ${ }^{3}$ Department of Neurosurgery, Medizinische Hochschule Hannover, Hannover, Germany ${ }^{4}$ Department of Neurosurgery, Yonsei University College of Medicine, Seoul, Republic of Korea

${ }^{5}$ Center for Focused Ultrasound, University of Zurich, Children's Hospital Zurich, Zurich, Switzerland

${ }^{6}$ Department of Neurosurgery, Kantonsspital St. Gallen, St. Gallen, Switzerland

\section{Correspondence to}

Dr Georg Kägi, Department of Neurology, Kantonsspital St.Gallen, St.Gallen 9007, Switzerland; georg.kaegi@ kssg.ch

Received 21 April 2017 Revised 18 September 2017 Accepted 20 November 2017 Published Online First 21 December 2017

Check for updates

To cite: Schreglmann SR Krauss JK, Chang JW, et al. J Neurol Neurosurg Psychiatry 2018:89:727-735.

\section{ABSTRACT}

For nearly a century, functional neurosurgery has been applied in the treatment of tremor. While deep brain stimulation has been in the focus of academic interest in recent years, the establishment of incisionless technology, such as MRI-guided high-intensity focused ultrasound, has again stirred interest in lesional approaches.

In this article, we will discuss the historical development of surgical technique and targets, as well as the technological state-of-the-art of conventional and incisionless interventions for tremor due to Parkinson's disease, essential and dystonic tremor and tremor related to multiple sclerosis (MS) and midbrain lesions. We will also summarise technique-inherent advantages of each technology and compare their lesion characteristics. From this, we identify gaps in the current literature and derive future directions for functional lesional neurosurgery, in particularly potential trial designs, alternative targets and the unsolved problem of bilateral lesional treatment. The results of a systematic review and meta-analysis of the consistency, efficacy and side effect rate of lesional treatments for tremor are presented separately alongside this article.

\section{INTRODUCTION}

Tremor is defined as an involuntary, oscillating sinusoidal movement of a body part. Its semiology is defined by the limb posture, during which it becomes apparent, frequency and body distribution. While tremor phenomenology of the most frequent aetiologies namely essential tremor (ET) and Parkinson's disease (PD) differ, they do share aspects of the underlying pathophysiology. ${ }^{12}$ Dystonic tremor has been increasingly appreciated as a frequent entity, ${ }^{3}$ while ischaemic, traumatic or inflammatory lesions to midbrain or cerebellar structures are alternative frequent causes of tremor. ${ }^{45}$

Although tremor represents the most frequent movement disorder, its treatment remains challenging, and oral medication have proven to be only partially successful. ${ }^{67}$ Until the advent of levodopa therapy in the mid 1960s, lesional neurosurgery was the mainstay of symptomatic treatment for PD-related tremor. It was the great success of levodopa and later of deep brain stimulation (DBS) that has led to a gradual decline in academic interest in lesional approaches over the following decades, while their efficacy remain appreciated. ${ }^{8}$ However, recent technological advances in the development of incisionless technology and especially MRI-guided high-intensity focused ultrasound (MRIgFUS) has led to a revived interest in lesional procedures for tremor. ${ }^{\text {' }}$

This article aims to summarise the historical development of lesional functional neurosurgery in the treatment of tremor disorders both with regards to targets and surgical technique. It also addresses and compares the surgical technique of radiofrequency (RF) ablation, Gamma Knife (GK) and MRIgFUS as well as the lesions characteristics created through them. Furthermore, we aim to address some of the emerging challenges to translate promising incisionless technology into treatment practice.

\section{Nomenclature}

Over time different thalamic nomenclature systems have been used and cited for the same structures. ${ }^{10}$ Due to the limited applicability of retrograde tracer studies to human tissue, it has been impossible to unanimously reconcile the anatomical, primate physiology and human neurosurgical nomenclature, which often creates confusion and particularly complicates the neurophysiological interpretation of surgical data. Hassler's nomenclature is still the most frequently used terminology in functional neurosurgery and is based on thalamic cytoarchitecture (see figure 1 ; camera lucida drawing adapted from $\mathrm{ref}^{11}$ ). Newer systems have tried to incorporate the findings in primates and to allow easier comparison between studies. In the following, Hassler's ventral intermediate nucleus (VIM) is used analogous to Walker's VIM and the more recent concept of the ventral lateral posterior nucleus (VLp) by Jones. Hassler's ventralis oralis anterior nucleus corresponds to Jones' ventral lateral anterior nucleus (VLa), while the ventralis oralis posterior nucleus (VOP) is considered a transition zone between VLa and VLp. ${ }^{10}$

Subthalamic structures, that is, the area directly caudal to the ventral thalamic nuclei, are referred to as the posterior subthalamic area (PSA). It is formed of the white matter tracts of the radiation prelemniscalis (Ra.prl), which includes the cerebellothalamic tract (CTT) and the nucleus of the caudal zona incerta (cZI). The ansa lenticularis and the fasciculus lenticularis compose the pallidothalamic tract, which is located in Forel's field $\mathrm{H} 2$ and which enters the thalamus as the fasciculus thalamicus in $\mathrm{H} 1$ (see figure 2; three-dimensional (3D) rendering from sagittal camera lucida drawings according to ref ${ }^{12}$ using Free-D software ${ }^{13}$; see the corresponding 3D version as an enhanced PDF in the online supplementary file). 


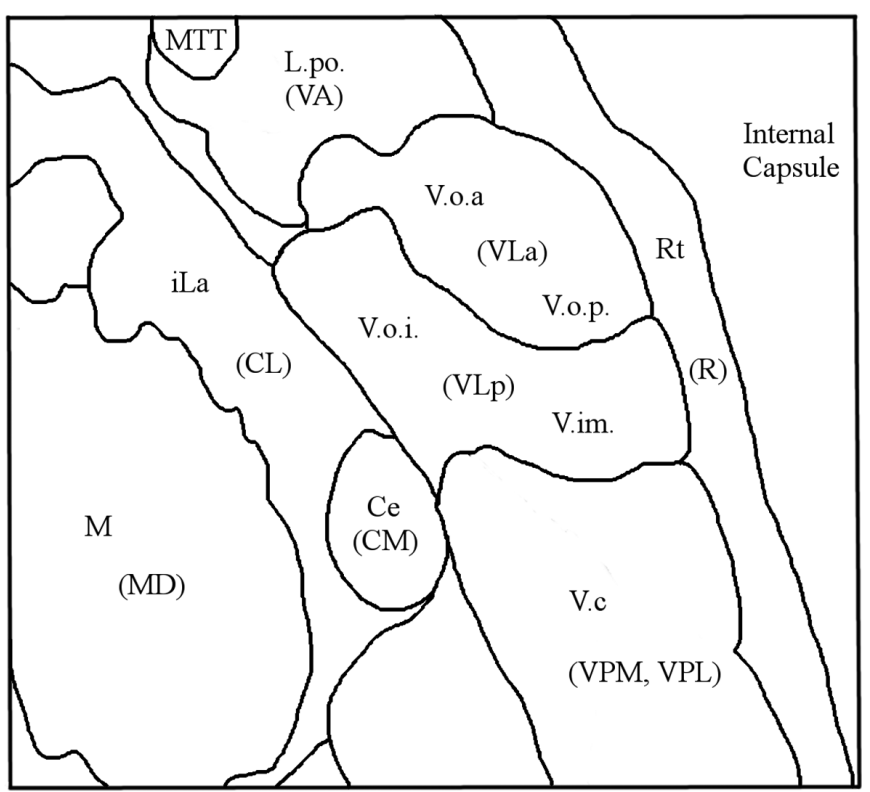

Figure 1 Human thalamus in the axial/horizontal plane, depicting the four main ventral thalamic subnuclei according to Hassler (in brackets (according to Hirai and Jones in double brackets)) from anterior to posterior: lateropolaris/ventral anterior nucleus (L.po. (VA)), ventro-oralis anterior and posterior/ventralis lateralis anterior (V.o.a. and V.o.p. (VLa)), ventrointermedius (V.im. (VIM)) and ventrocaudalis/ ventralis posteriormedialis and ventralis posterolateralis (V.c (VPM and VPL). Adjacent structures include the nucleus centralis thalami (Ce (CM)), nucleus medialis dorsalis (M (MD)), nucleus intralamellaris (iLa (CL)), as well as the mamillothalamic tract (MTT), reticulatum thalami (Rt (R)) and internal capsule; camera lucida drawing adapted from ref ${ }^{11}$.

\section{HISTORY AND DEVELOPMENT OF TARGETS}

The origin of functional neurosurgery for movement disorders dates back to the beginning of the 20 century, when lesions

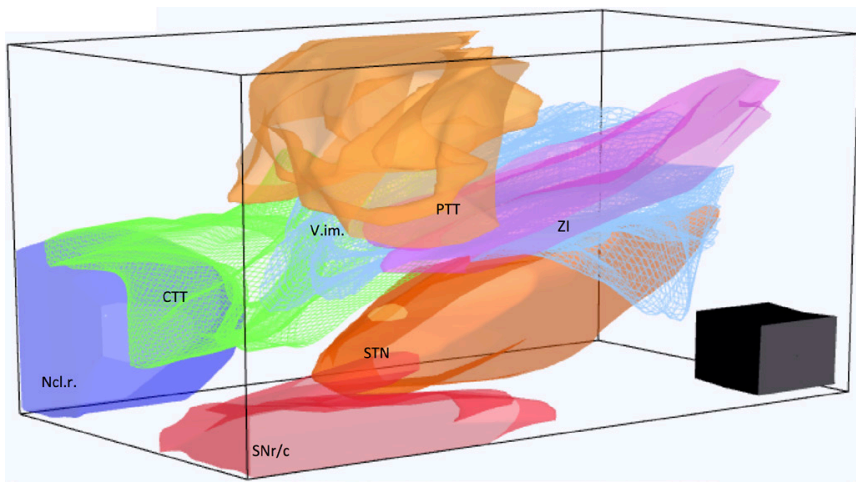

Figure 2 Anatomy of subthalamic/thalamic basal ganglia and adjacent structures relevant in lesional functional stereotactic neurosurgery for tremor: Visualisation of the posterior subthalamic area (PSA) containing the zona incerta $(\mathrm{ZI})$ and the prelemniscal radiation, containing both cerebellothalamic (CTT) and pallidothalamic tract (PTT). The PSA is limited rostrally by the ventral thalamus and its ventrointermedial nucleus (V.im.), mediocaudally by the nucleus ruber (Ncl.r.), caudolaterally by the substantia nigra (SNr/c) and caudoventrally by the subthalamic nucleus (STN). Threedimensional-rendering from sagittal camera lucida drawings according to ref ${ }^{12}$ using Free-D software. ${ }^{13}$ Scale cube side length: $2 \mathrm{~mm}$. The enhanced PDF of this figure in the online supplementary material allows manipulation of the 3D rendering for improved anatomical display (open PDF with Acrobat Reader). aiming at parts of the corticospinal system were used to alleviate motor symptoms. The procedures included initial attempts at spinal rhizotomies at the nerve root level, anterolateral cordotomies at the spinal level ${ }^{14}$ and with time extended to pyramidotomies, ${ }^{15}$ pedunculodotomies, ${ }^{16}$ mesencephalic tractotomies ${ }^{17}$ and even motor cortex excisions. ${ }^{18}$ Although authors acknowledged the drastic expense of spastic paresis due to lesion of the first motor neuron, academics at the time followed eminent Paul Bucy's dogmatic notion that the abolishment of tremor was 'impossible without the interruption of the pyramidal system'. ${ }^{19}$ It is now recognised that the establishment of the concept of the 'extrapyramidal' motor system originates from Spatz's article from $1927,{ }^{20}$ which laid the foundation for the treatment of motor symptoms without causing pyramidal weakness.

\section{Initial basal ganglia attempts}

Meyers performed the first transventricular caudate nucleus resection for postencephalic tremor in 1939 and ventured further including the anterior limb of the internal capsule, ansa lenticularis and the pallidum in the following years. ${ }^{21}$ This for the first time allowed basal ganglia resections without damaging pyramidal structures, suppressing tremor without causing paresis. At 2-year follow-up, he reported $62 \%$ successful tremor suppression. ${ }^{22} \mathrm{~A}$ more refined way of targeting the ansa lenticularis using electrocoagulation was deployed by Fenelon. ${ }^{23}$

Although the first means to localise human brain structures had been published just before the turn of the century, ${ }^{24}$ the first stereotactic procedure on a patient with Huntington's chorea was performed by Spiegel and Wycis only in $1947 .{ }^{25}$ The first stereotactic pallidotomy followed shortly thereafter, introducing this technique to the treatment of movement disorders. ${ }^{26}$ The first cases of electrocoagulation of the ansa lenticularis reported a $78 \%$ improvement of PD tremor. ${ }^{27}$ In parallel, Cooper by accident observed the amelioration of tremor and rigidity in a postencephalic patient with PD by damaging and ligating the anterior choroidal artery during an attempted pedunculotomy. ${ }^{28}$ Meanwhile Guiot and Brion already presented the results of the lesion of the pars interna of the globus pallidum (GP) in a series of 27 patients, resulting in an improvement in tremor and other motor symptoms in $42.5 \%$ of the cases. ${ }^{29}$ In due course, chemopallidotomy, consisting of the installation of alcohol directed at the GPi through a transtemporal burr hole and catheter, at that time a free-hand procedure under pneumoencephalography control, was developed. ${ }^{30}$ Similarly and independently, Narabayashi and Okuma ${ }^{31}$ performed the first pallidotomy procedures in Japan using a mixture of procaine and wax. Cooper's chemopallidectomies, although resulting in lesions of considerable variability in size and location on postmortem analysis, were reported to improve tremor in $75 \%$ of cases. ${ }^{32}$ In parallel to chemopallidotomy, various groups around the globe were developing and refining stereotactic apparatuses to improve the navigation of electrocoagulation devices. ${ }^{33}$ Already at that time a functional subcompartmentalisation of the GP started to became apparent: in the conclusion of a series of 100 'pallido-ansotomies' placed in the region of the ansa lenticularis/medial GP, a target 3-6 $\mathrm{mm}$ behind the anterior commissure appeared to be most effective in treating rigidity and tremor ${ }^{34}$ or even $9 \mathrm{~mm}$ behind the anterior commissure in cases of severe tremor. ${ }^{33}$

Although overshadowed by the success of thalamotomy on tremor treatment and largely ignored at the time, the seminal work of Svennilson and Leksell showed that interventions in the posteroventral GPi resulted in a much more consistent benefit on tremor than anterior placed lesions. ${ }^{35}$ Only in retrospect, data 
on Leksell's success of his continued focus on the posteroventral pallidum (PVP) was recognised. ${ }^{36}$ Some authors identified larger lesion size, a baseline of mental retardation and advanced disease as risk factors for cognitive side effects of bilateral procedures, while Gillingham was the first to stress the importance of precise placement of the lesion over gross lesion size as a predictor of safety and efficacy. ${ }^{37}$

Ultimately, RF lesioning with temperature control became the method to replace all other technology.

\section{Early thalamic experience}

Guided by his research on the thalamus, Hassler came to the conclusion that targeting both the pallidothalamic and dentatothalamic system would be most useful in treating tremor, ${ }^{38}$ choosing the VOP as an appropriate target. Subsequently, Mundinger and Riechert performed the first motor thalamotomy in 1952 in a 38-year-old man with postencephalitic PD and severe tremor with great success, ${ }^{39}$ opening a decade of thalamotomies in the treatment for $\mathrm{PD}^{40}$ and other hyperkinetic disorders. ${ }^{41}$ It was only several years later, however, that the VIM was identified as the optimal target for tremor and that the pallidum was almost completely abandoned as a target. This has been corroborated in large series, ${ }^{42}$ and the GPi has not been targeted for sole tremor amelioration since.

\section{Early subthalamic literature}

When reviewing subthalamic approaches, one needs to differentiate between lesions to fibre tracts in the PSA, to the cZI and to the subthalamic nucleus (STN) itself. Already in 1953, the first cases of electrocoagulation of the ansa lenticularis were published in an attempt to decrease the lesion size necessary to reduce tremor. ${ }^{43}$ To avoid damage to the internal capsule and anterior choroidal artery, the campotomy procedure was developed by placing the lesion at the junction of the ansa and fasciculus lenticularis in Forel's field $\mathrm{H}$ with a significant reduction in tremor $(88 \%)$ and rigidity $(68 \%)$ in patients with $\mathrm{PD} .{ }^{44} \mathrm{~A}$ series of 100 electrode insertions in 58 patients with tremor-dominant PD showed the highest efficacy in tremor reduction for a lesion placed in the PSA. ${ }^{45}$ Mundinger played an influential role to establish the cZI as a target and documented this in a large study, reporting a $68 \%-75 \%$ rate of hand tremor suppression after cZI lesions in 456 patients. ${ }^{46}$ This was further detailed by results from a mixed tremor cohort, in which the most effective target location was shown to be the most posterior and inferior portion of the cZI, containing the Ra.prl. ${ }^{47}$ From a similar series, it was concluded that lesion placement in the PSA allowed for a smaller lesion size $\left(40-60 \mathrm{~mm}^{3}\right)$ with greater efficacy on tremor and better safety than larger thalamic lesions. ${ }^{48}$ However, with the advent of levodopa-based medical therapies from the late $1960 \mathrm{~s},{ }^{49}$ interest in invasive surgical treatment dropped precipitously for decades.

\section{Methodological shortcomings of the early literature}

In this pre-CT/MRI era, pneumencephalography and later ventriculography were used for targeting, and postmortem analysis was the only reliable tool to confirm targeting precision, which occasionally revealed significant misplacements. ${ }^{32}$ When assessing clinical outcome in the first decades of functional neurosurgery for movement disorders, one always needs to bear in mind the systematic shortcomings of the early literature with regards to (1) clinical diagnosis, (2) target selection, (3) lack of physiological target identification, (4) inhomogeneous lesioning technique, (5) targeting precision and (6) lesioning size, as well as (7) non-standardised identification of (8) immediate and longterm benefits and (9) side effects by non-impartial investigators. ${ }^{50}$ We therefore agree with Guridi and Lozano that multiple limitations of the early lesional literature hamper a meaningful systematic interpretation of results. ${ }^{50}$

\section{0s revival of lesional approaches}

There were only few lesional tremor studies aiming at the thalamus published during the $1980 \mathrm{~s},{ }^{51}{ }^{52}$ although thalamotomies were continued to be performed in specialised centres worldwide. It was not until the early 1990s that lesional approaches re-emerged, primarily due to the recognition of levodopa-induced dyskinesia (LID) as sequelae of long-term oral levodopa treatment in PD and the rediscovery of alternative targets. At the same time, the increased insight into basal ganglia pathophysiology gained through the MPTP monkey model provided a much more detailed rationale for lesional interventions. ${ }^{53} \mathrm{PVP}$ was reintroduced for treatment of PD after nearly 30 years of dormancy, and while this procedure drastically decreased LID, it also improved tremor. ${ }^{36}$

With the advancing understanding of the basal ganglia circuitry by studies of the MPTP primate model in the late 1980s, ${ }^{54}$ targeting the overactive STN and in particular its dorsolateral sensorimotor region emerged as a novel target strategy that was particularly attractive for DBS. It had been well known already at that time that in healthy individuals, a lesion to the STN invariably causes haemiballism. In PD, however, it was shown that the threshold for surgery-induced dyskinesia is increased due to altered striatopallidal activity patterns following the hypodopaminergic state. ${ }^{55}$ After promising primate lesional ${ }^{56}$ and human DBS studies,${ }^{57}$ a string of small studies also showed a beneficial effect with unilateral ${ }^{58-62}$ and bilateral lesions of the dorsolateral portion of the STN on PD motor features including tremor. ${ }^{5563}$ Although staged bilateral procedures were described not to cause severe dyskinesia and ataxia, ${ }^{63}$ simultaneous bilateral lesions did. ${ }^{55}$ Similarly, lesional procedures were tested again for tremor beyond PD as treatment success with oral medication remained limited. Increasingly Multiple Sclerosis- and rubral tremor were studied once more both with DBS and lesioning.

Since the late 1980s, clinical data from well designed trials shifted the academic focus onto DBS ${ }^{64}$ and, with the progressive improvement of technology, stimulation replaced lesional protocols in the academic setting. Only very recently there has been again increasing interest in lesional approaches, as promising results from prospective trials with incisionless GK and MRIgFUS thalamotomy in ET were published. ${ }^{65-69}$

\section{TECHNOLOGY}

The following paragraphs summarise the currently available techniques for lesional treatments; table 1 displays their inherent conceptual advantages and disadvantages.

\section{RF ablation}

As described above, many of the conventional techniques for tissue lesioning, such as chaemolysis, procain wax infusion or cutting using a stylette, were developed and then replaced by more advanced methods over time. RF ablation influenced lesional functional neurosurgery more than any other method and is still widely used around the globe today. ${ }^{70}$ In principal, a $\mathrm{RF}$ electrode is introduced under stereotactic guidance via a burr hole to the target chosen to create a monopolar electrocoagulation lesion, and among stereotactic neurosurgeons, the original publication still serves as a guidance to the technical basis of 
Table 1 Conceptual and practical differences between state-of-the-art lesional functional neurosurgery technique

\begin{tabular}{|c|c|c|c|c|c|c|}
\hline & \multicolumn{2}{|l|}{ Radiofrequency ablation } & \multicolumn{2}{|c|}{ Gamma Knife radiosurgery } & \multicolumn{2}{|c|}{$\begin{array}{l}\text { MRI-guided high-intensity focused } \\
\text { ultrasound }\end{array}$} \\
\hline & Advantages & Disadvantages & Advantages & Disadvantages & Advantages & Disadvantages \\
\hline Preparation & $\begin{array}{l}\text { Shaving directly around burr } \\
\text { hole only }\end{array}$ & Stereotactic frame needed & No head shaving & $\begin{array}{l}\text { Stereotactic frame } \\
\text { needed }\end{array}$ & & $\begin{array}{l}\text { Stereotactic frame } \\
\text { needed head shaving } \\
\text { compulsory }\end{array}$ \\
\hline $\begin{array}{l}\text { Target verification } \\
\text { and adjustment }\end{array}$ & $\begin{array}{l}\text { Possibility for } \\
\text { electrophysiological target } \\
\text { verification and adjustment } \\
\text { (microrecording or } \\
\text { macrostimulation) }\end{array}$ & $\begin{array}{l}\text { Bleeding risk increases } \\
\text { with multiple recording } \\
\text { trajectories }\end{array}$ & & $\begin{array}{l}\text { No electrophysiological } \\
\text { target verification } \\
\text { no means for target } \\
\text { adjustments }\end{array}$ & $\begin{array}{l}\text { Target adjustable during } \\
\text { iterative sonications } \\
\text { based on clinical or real- } \\
\text { time imaging feedback }\end{array}$ & $\begin{array}{l}\text { No electrophysiologica } \\
\text { target verification }\end{array}$ \\
\hline Intervention & $\begin{array}{l}\text { Approximate intervention } \\
\text { duration*: } 60-120 \mathrm{~min}\end{array}$ & $\begin{array}{l}\text { Burr hole needed potential } \\
\text { brain shift, infection and } \\
\text { bleeding risk trajectories } \\
\text { traversing healthy tissue }\end{array}$ & $\begin{array}{l}\text { Incisionless } \\
\text { approximate } \\
\text { intervention } \\
\text { duration*: } \\
15-60 \text { min }\end{array}$ & & $\begin{array}{l}\text { Incisionless real-time } \\
\text { control of target } \\
\text { voxel position and } \\
\text { temperature via MRI } \\
\text { iterative confirmation of } \\
\text { final sonication settings }\end{array}$ & $\begin{array}{l}\text { Prolonged placement } \\
\text { in supine position } \\
\text { vertigo/nausea in } \\
\text { some patients during } \\
\text { sonication in supine } \\
\text { position approximate } \\
\text { intervention } \\
\text { duration.*: } \\
180-300 \text { min (own } \\
\text { data) }\end{array}$ \\
\hline
\end{tabular}

*Intervention duration: from local anaesthesia to frame removal.

the procedure. ${ }^{71}$ Impedance measurements guide the surgeon as to whether the exposed tip of the electrode resides in grey or white matter. Microelectrode recording and macrostimulation are frequently used to improve probe placement, although not deemed essential by some authors. ${ }^{72}$ After target verification, temperature and time are set according to the target (thalamotomy $70^{\circ} \mathrm{C}$ applied for max. 60 s; pallidotomy $75^{\circ} \mathrm{C}-80^{\circ} \mathrm{C}$ applied for max. $60 \mathrm{~s}$ ) and energy is applied. To avoid potentially dangerous tissue bubble formation, the current is ramped up slowly during the latter. ${ }^{71}$ The incidence of asymptomatic haemorrhage with RF ablation is reported as high as $29 \%{ }^{73}$

\section{INCISIONLESS TECHNIQUES}

Conventional stereotactic procedures including DBS depend on the introduction of an instrument along a calculated trajectory and through surrounding tissue. The invariable opening of the skull via a burr hole introduces the risk to infection and brain shift with possible subsequent targeting inaccuracy. The surgical trajectory needs adequate planning to avoid damage to structures in its course. Non-invasive techniques aim at circumventing all of the above.

\section{Gamma Knife}

During radiosurgery focused radiation energy is translated into tissue necrosis in the focus without damaging adjacent tissue. Since its first application in $1968,{ }^{74}$ GK has been continuously refined and amended to functional neurosurgery, while the bulk of its clinical application remains in the treatment of vascular malformation and tumours. ${ }^{75}$ Over time, investigators reduced the radiation energy to create lesions from initially 180-200 Gy to $130-140 \mathrm{~Gy}$, and it is now accepted that $120 \mathrm{~Gy}$ is the minimum dose needed to evoke definite tissue changes. White matter fibre tracts however are far more susceptible to radiation energy, and there is general agreement that doses to the internal capsule should not excess 2025 Gy; therefore, PVP is not performed with GK due to the proximity of the target to the highly radiosensitive optic tract. The procedure does not allow for direct, that is, electrophysiological, nor indirect, that is, imaging-based target and lesion verification during the intervention. It is therefore key to limit the geometrical distortion on
MRI-based preinterventional planning during procedure planning. ${ }^{75}$ The delayed onset of a clinical effect after treatment-to be expected 3 to 6 months after the intervention ${ }^{76-78}$-and the inability to monitor the target tissue during the intervention, are inherent conceptual disadvantages.

\section{MRI-guided high-intensity focused ultrasound}

The first attempt to create lesions in the pallidal network using a single ultrasound source dates back to 1958 . With the advance of technology, high-intensity focused ultrasound ablation was introduced again during the 1980s and initially developed for gynaecological and urological interventions. The first study using the commercially available InSightec Neuro platform reported the safe application of MRIgFUS to create thalamic lesions for neuropathic pain. ${ }^{79}$ During the MRIgFUS intervention, the awake patient wearing the helmet-shaped ultrasound transducer is positioned in a 3T-MRI, which allows target verification and temperature control within the target voxel via Magnetic Resonance (MR) thermometry sequences in real time. The application of sonic energy (called 'sonication') for $10-20 \mathrm{~s}$ is followed by pauses for cooling and clinical assessment. Sonication energy is then increased in a stepwise manner until reaching temperature changes resulting in tissue effects. ${ }^{79}$ Once this temperature threshold is reached (approximately $60^{\circ} \mathrm{C}$ for VIM). there is immediate anatomical and clinical effect, ${ }^{676879}$ which are the most important advantages of this technology over radiosurgery. In 2013, two open-label, prospective interventional studies assessed the effect of non-invasive VIM lesioning on tremor. ${ }^{6768}$ The promising results have since been replicated both for the VIM as well as the CTT in the PSA. ${ }^{650} \mathrm{~A}$ large skull volume and low skull density ratio are technology-related treatment limitations. ${ }^{81}$ So far, only a single haemorrhage ${ }^{79}$ has been reported after 130 published MRIgFUS tremor interventions.

\section{Lesion comparison}

Empirically, volumetric quantification of stereotactic lesions differentiates three concentric parts, representing the inner and middle zone (necrosis) and outer zone (oedema). ${ }^{82}$ The method and size of lesions reported in the literature is variable: for example, RF thalamic (VIM) ${ }^{83}$ and subthalamic lesions ${ }^{48}$ 


\section{$\begin{array}{llll}\text { 24-72h } & 1 \text { Month } & 6 \text { Months } & 12 \text { Months (+) }\end{array}$}

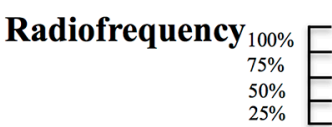

Volume

MRI (T2)

Histology

\section{Gamma Knife}

Volume

MRI (T2)

Histology

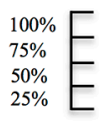

Volume

MRI (T2)

Histology
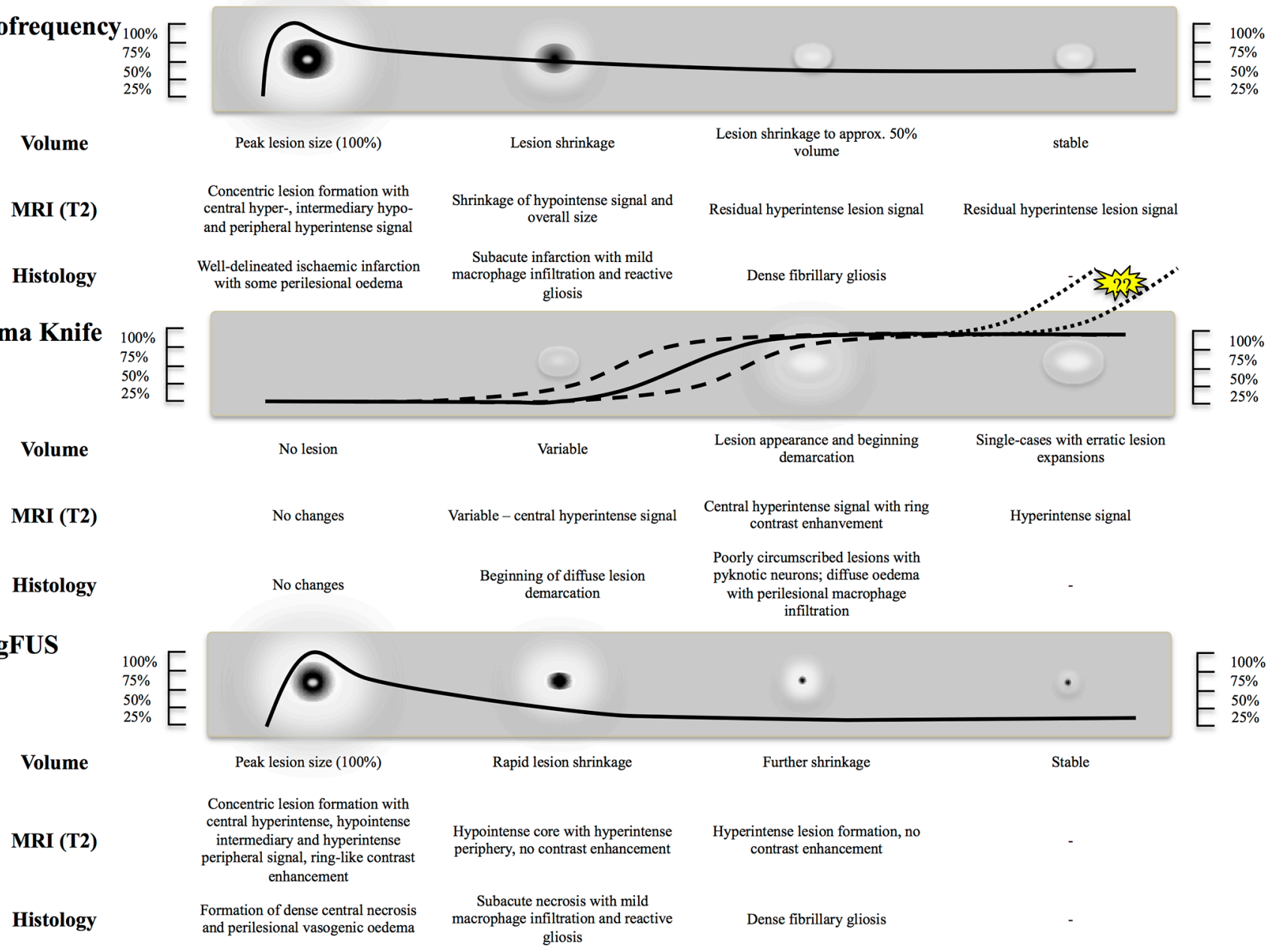
central hyper-, intermediary hypoand peripheral hyperintense signal

of hypointense
overall size

Residual hyperintense lesion signal

Residual hyperintense lesion signal

\section{Well-delineated ischaemic infarction}

Subacute infarction with mild with some perilesional oedema macrophage infiltration and reactive gliosis

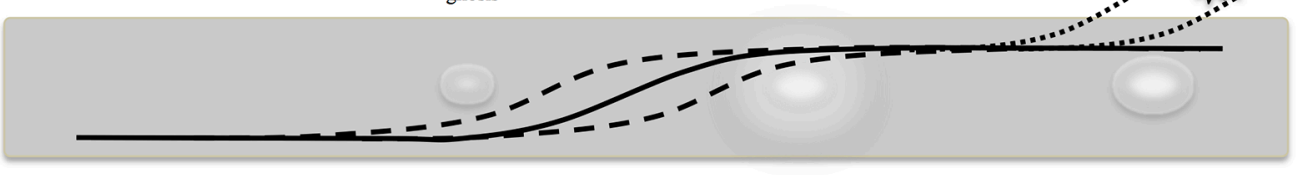
infiltration

Figure 3 Comparison of effects between state-of-the-art lesional functional neurosurgery techniques (radiofrequency, Gamma Knife radiosurgery and MRI-guided high-intensity focused ultrasound (MRIgFUS) ablations) on the evolution of lesion size, MRI and histological characteristics over time. Dense line drawing depicting lesion volume over time with dotted line depicting variable development. Scale refers to percentage of intended lesion volume size.

have been reported between $40 \mathrm{~mm}^{3}$ and $60 \mathrm{~mm}^{3}$, lesions to the cZI have been reported at $18 \mathrm{~mm}^{3}$ in size after 11 years of follow-up ${ }^{84}$ and lesions to the GPi $65.5 \mathrm{~mm}^{3}$ at 4 months ${ }^{85}$ and $40 \mathrm{~mm}^{3}$ after $4-6$ months follow-up. ${ }^{86}$ Leucotome thalamic lesions have been reported around $400-500 \mathrm{~mm}^{3}$ size without reporting side effects. ${ }^{87}$ Given the inconsistencies in the neurosurgical literature with regards to the exact technique and time-point of volume quantification, the interpretation of these drastically different lesion sizes between studies is difficult if not impossible. Two studies that assessed the relationship between lesion size and clinical effect reported no correlation between the two for both pallidotomy and thalamotomy. ${ }^{88} 89$

The only study directly comparing the in vivo effect of RF $\left(72^{\circ} \mathrm{C} \times 60\right.$ s), MRIgFUS (maximum temperature $55^{\circ} \mathrm{C}-60^{\circ} \mathrm{C}$ ) and GK (130-160 Gy) on porcine thalamic tissue reported similar MR and histological tissue changes for RF and MRIgFUS with formation of peak lesion volumes within 72 hours after the intervention and subsequent formation of well-demarcated reactive gliosis. ${ }^{90}$ These lesions then shrink over time most likely due to scarring, and in humans, these lesions reach a plateau around 6 months after the $\mathrm{RF}^{91}$ and 3 months after the MRIgFUS interventions. ${ }^{65} 9293$

GK lesions differ in both the temporal as well as volumetric and histological evolution, as they are more diffuse, evolve over months ${ }^{94}$ and induce diffuse macrophage infiltration to adjacent anatomical structures. ${ }^{90}$ Volumetric quantification in humans indicates a peak lesion size at 6-9 months after GK lesioning. ${ }^{9496}$ Microelectrode recordings from a limited number of patients suggest that the T2-hypointense core region represents the directly irradiated zone, while the surrounding irregular T2-hyperintense region is not functionally damaged. ${ }^{77}$ Tissue reaction can vary, and delayed effects months after the actual treatment have been repeatedly reported, resulting in drastically different lesion sizes between $188 \mathrm{~mm}^{3}$ and $871 \mathrm{~mm}^{397}$ with exceptional cases as large as $2030 \mathrm{~mm}^{3}$ after 36 months $^{98}$ or $>6000 \mathrm{~mm}^{3}$ after 18 months $^{95}$ (see figure 3). After GK VIM thalamotomy cases without side effects showed smaller lesion sizes of $188 \pm 224 \mathrm{~mm}^{3}$ $\left(\mathrm{n}=157\right.$ procedures) than cases with side effects: $871 \pm 742 \mathrm{~mm}^{3} .{ }^{37}$ Delayed adverse effects of GK lesioning due to unexpected large lesions has been reported in $7.7 \%,{ }^{99}$ respectively $6.9 \%$ of cases. ${ }^{97}$ Corticosteroids have no documented effect for these effects, which are mostly described as self-limiting over 12-18 months. ${ }^{97}$ Serious adverse events can develop after interventions with doses from 140 Gy onwards. ${ }^{100}$ It is argued that this is due to individual radiosensitivity, which still cannot be predicted on an individual basis. ${ }^{66}$

\section{Consistency, clinical efficacy and side effect rate}

The clinical effect of different lesional interventions for tremor has never been formally and comprehensively assessed and 
compared between targets and indications. So far the literature has been summarised in a narrative way only, calling for an unbiased analysis of the existing literature.

To this end, we have undertaken a systematic review and meta-analysis according to a published, peer-reviewed protocol ${ }^{101}$ in accordance to the recommendations from the Preferred Reporting Items for Systematic Review and Meta-Analysis Protocols 2015 statement. This systematic review protocol has been registered in the International Prospective Register of Systematic Reviews on 20 September 2016 (CRD42016048049). The resulting meta-analysis covers published, peer-reviewed literature from 1990 to 2017 of lesional tremor treatments Schreglmann et al. ${ }^{102}$ It systematically summarises consistency, efficacy and side effect rate of lesional interventions according to tremor aetiology, lesion target and lesion technique in detail, which therefore are not discussed in this work.

\section{Future directions}

The recent introduction of MRIgFUS technology with its potential advantages has stirred considerable interest in the movement disorder field, and it is conceivable that this might lead to a partial renaissance of lesional functional neurosurgery for tremor and possibly other disorders. The need for prospective, blinded, controlled trials has been acknowledged by leading figures in the field, ${ }^{9} 103$ and the first blind-assessed, prospective studies have been published. ${ }^{69} 93$ This however can only be the beginning of the establishment of a solid evidence base to explore the potential of this very promising technology. With the number of operational MRIgFUS centres (2017: 30 centres, 800 treatments; personal communication InSightec) increasing worldwide, we are hopeful that very soon additional trial data are published, as it would be premature to judge the available data on safety, consistency and efficacy substantial enough to draw final conclusions. In addition to clinical safety and efficacy, intervention cost is another important factor for the widespread implementation of a novel neurosurgical technique. The fact that incisionless approaches do not rely on implantable hardware needing replacement at some point in the future, as well as a less intensive aftercare needed, could in the long run counterbalance the still high cost to acquire treatment devices. First data comparing DBS, GK and MRIgFUS showed significantly lower projected costs for both incisionless techniques compared with DBS. ${ }^{104}$

We hope that the current excitement in the wake of the early FDA approval will boost its continued scientific investigation and does not lead to indiscriminate use before credible evidence of substantial size has accumulated; ideally, therefore, all patients undergoing MRIgFUS treatment should be enrolled in trials and treatment registers.

\section{Trial design}

The majority of published lesional functional neurosurgery studies for tremor carry methodological limitations with regards to prospective trial design, independent, validated symptom quantification, adequate follow-up and description of tremor recurrence and side effects. It is imperative to deliver prospective trials with standardised, video-documented outcome evaluation by independent and blinded movement disorder neurologists using validated evaluation instruments. Similarly, side effects should be documented in a standardised way.

The direct comparison of open neurosurgery with non-invasive MRIgFUS or GK poses methodological problems as (A) double-blind assessments are difficult due to instrumentation, which cannot be concealed from the patient and (B) as bilateral procedures are standard for DBS but still considered to carry a higher risk for lesional approaches. Several strategies could help circumventing such obstacles, including (A) stringent single-blinded assessments aiming at compensating for the fact that a reasonable blinding of patients with regards to the method of intervention is simply impossible, ${ }^{105}$ (B) delayed start of stimulation contralateral to the studied side after bilateral DBS implantation minimising stimulation artefacts on the studied side without the need for a second operation (provided the microlesioning effect after electrode implantation is taken into account ${ }^{106}$ ) and (c) considering and addressing important and potentially confounding placebo, nocebo and lessebo effects by adequate trial design. ${ }^{107}$ Finally, changes in quality of life and level of functioning should be reported as a standard and should be included as primary outcome variables in future tremor trials.

\section{Bilateral treatment}

Probably the biggest constraint with lesional surgery in the past and foreseeable future is bilateral treatment, since irrespective of the target, bilateral lesion surgery dramatically increases the risk to cause dysarthria and dysphagia. ${ }^{72} 108-111$ The exact mechanism for this is still unclear. While it is assumed that lesion spread to corticobulbar fibres constitutes a major factor, a disturbance of the corticobasal ganglia-thalamo-cortical loop is believed by some to play a role as well. Our meta-analysis (reference to Schreglmann et al systematic review and meta-analysis manuscript handled by same editor, currently under parallel revision with the journal) for the first time allows to quantify the degree to which this risk increases according to target, tremor aetiology and lesional technique used.

While experience from the past precludes investigators from further bilateral treatment attempts with RF ablation or GK radiosurgery, MRIgFUS would potentially allow for more precise targeting and/or titrating the final lesion by a multistep procedure to avoid interference with corticobulbar fibres. In this regard, the possibility of staged bilateral interventions, as successfully pioneered by Young in 42 patients treated with RF at the VIM without a single complication, ${ }^{97}$ is currently explored by various groups; a first uncontrolled, retrospective study reports this possibility for MRIgFUS in ET. ${ }^{80}$ In addition to technique and aetiology, finding the optimal anatomical target is of additional importance. Irrespective of the prior, prospective studies of bilateral interventions should include speech and swallowing, as well as gait assessments to monitor the incidence and quantify the severity of these potential side effects.

\section{Reappraisal of the posterior subthalamic area}

As one of the historically established tremor targets, the PSA was entertained by neurosurgeons who thought the higher density of fibres connecting the cerebellar output nuclei and the VIM thalamic nucleus as well as its larger anatomical distance to vulnerable structures within the vicinity, that is, sensory thalamic nuclei and internal capsule, to be of conceptual advantage, as reviewed in $\mathrm{ref}^{112}$. It has recently been trialled again using MRIgFUS with a favourable effect and side effect profile. ${ }^{80} 93$ In particular, the very low rate of persistent side effects without paraesthesia could serve as first support to the conceptual advantages mentioned. In addition, collective evidence from DBS studies also indicates that the best stimulation effect on tremor is achieved in the white matter tracts of the PSA directly caudal to the VIM rather than the VIM itself. ${ }^{112-117}$ Although this of course has to be confirmed in larger samples and compared with 
other targets, it serves as an example that state-of-the-art technology can be used to reappraise established but out-of-fashion targets in order to optimise treatment options.

\section{CONCLUSION}

Theoretical advantages and promising clinical data on safety and efficacy of incisionless procedures currently build up momentum to reappraise lesional interventions as treatment strategies for tremor disorders once more. Given the still small number of published cases, the evidence base for incisionless lesional treatment however has to be substantiated. The exciting technical possibilities especially of MRIgFUS should be geared to close various gaps in the existing literature highlighted in this review and to further advance our knowledge base for treatment decisions. Together with our meta-analysis on lesional tremor treatments (reference to Schreglmann et al systematic review and meta-analysis manuscript handled by same editor, currently under parallel revision with the journal), this work summarises the current state of the art in lesional functional neurosurgery for tremor disorders. It also highlights the need for adequately designed prospective trials to support the existing data on safety and efficacy for established targets such as the VIM nucleus and for rediscovered targets within the PSA. Ultimately, only carefully designed head-to-head comparison trials will be able to answer the question if incisionless lesional approaches without the need for open surgery and device implantation, such as with MRIgFUS, are comparable with established DBS surgery.

Acknowledgements SRS is supported by grants by the Swiss Science Foundation, the Swiss Neurological Society and the European Academy of Neurology.

Contributors SRS initiated the project, generated the figures and wrote the manuscript draft. JKK wrote several manuscript chapters and critically reviewed the manuscript. JWC critically revised several manuscript chapters and reviewed the manuscript. SH-L, BW and EM critically reviewed the manuscript. KPB provided input on manuscript structure and critically reviewed the manuscript. GK initiated and supervised the project and critically reviewed the manuscript. All authors agreed on the final manuscript draft.

Competing interests None declared.

Provenance and peer review Not commissioned; externally peer reviewed.

(c) Article author(s) (or their employer(s) unless otherwise stated in the text of the article) 2018. All rights reserved. No commercial use is permitted unless otherwise expressly granted.

\section{REFERENCES}

1 Brittain JS, Cagnan H, Mehta AR, et al. Distinguishing the central drive to tremor in Parkinson's disease and essential tremor. J Neurosci 2015:35:795-806.

2 Cagnan H, Little S, Foltynie T, et al. The nature of tremor circuits in parkinsonian and essential tremor. Brain 2014;137:3223-34.

3 Gövert F, Deuschl G. Tremor entities and their classification: an update. Curr Opin Neurol 2015;28:393-9.

4 Alusi SH, Aziz TZ, Glickman S, et al. Stereotactic lesional surgery for the treatment of tremor in multiple sclerosis: a prospective case-controlled study. Brain 2001:124:1576-89.

5 Raina GB, Cersosimo MG, Folgar SS, et al. Holmes tremor: clinical description, lesion localization, and treatment in a series of 29 cases. Neurology 2016;86:931-8.

6 Lyons KE, Pahwa R. Pharmacotherapy of essential tremor : an overview of existing and upcoming agents. CNS Drugs 2008;22:1037-45.

7 Deuschl G, Raethjen J, Hellriegel H, et al. Treatment of patients with essential tremor. Lancet Neurol 2011;10:148-61.

8 Zesiewicz TA, Elble RJ, Louis ED, et al. Evidence-based guideline update: treatment of essential tremor: report of the Quality Standards subcommittee of the American Academy of Neurology. Neurology 2011;77:1752-5.

9 Deuschl G. New hope for severe essential tremor? Lancet Neurol 2013;12:420-2.

10 Krack P, Dostrovsky J, llinsky I, et al. Surgery of the motor thalamus: problems with the present nomenclatures. Mov Disord 2002;17 Suppl 3:S2-8.

11 Morphology JEG. nomenclature and connections of the thalamus and basal ganlia. In: Krauss JK, Jankovic J, Grossman RG, eds. Surgery for Parkinsons disease and movement disorders. Philadelphia: Lippincott Williams \& Wilkins, 2001
12 Gallay MN, Jeanmonod D, Liu J, et al. Human pallidothalamic and cerebellothalamic tracts: anatomical basis for functional stereotactic neurosurgery. Brain Struct Funct 2008;212:443-63

13 Andrey P, Maurin Y. Free-D: an integrated environment for three-dimensional reconstruction from serial sections. J Neurosci Methods 2005; 145:233-44.

14 Foerster T. Resection of the posterior spinal nerve-roots in the treatment of gastric crises and spastic paralysis. Proc $R$ Soc Med 1911:4-254.

15 Oliver LC. Surgery in Parkinson's disease; division of lateral pyramidal tract for tremor; report on 48 operations. Lancet 1949;1:910-3.

16 Walker AE. Cerebral pedunculotomy for the relief of involuntary movements. II. Parkinsonian tremor. J Nerv Ment Dis 1952:116:766-75.

17 Guiot G, Pecker J. Tractotomie mesencephalique anterieure pour tremblement parkinsonien. Rev Neur 1949;81:387-9.

18 Bucy PC. Cortical extirpation in the treatment of involuntary movements. Am J Surg 1948:75:257-63.

19 Crevier P. Experiences with different pallidotomy procedures. In: E H, N B, ed. The Shaking Palsy. Montreal: CreateSpace Independent Publishing Platform, 1960:121-2.

20 Spatz H. Spezielle Physiologie des Zentralnervensystems der Wirbeltiere. Berlin: J Springer, 1927

21 Meyers R. Surgical procedure for postencephalitic tremor, with notes on the physiology of the premotor fibres. Arch Neurol Psychiatry 1940;44:455-9.

22 Meyers R. Historical background and personal experiences in the surgical relief of hyperkinesia and hypertony. Fields WS, ed. Pathogenesis and treatment of Parkinsonism: Springfield, 1958:229-70

23 Fenelon F. Essai de traitment neurochirurgical du syndrome parkinsonien par intervention directe sur les voies extrapyramidales immediatement sousstriopallidales (anse lenticulaires). Rev Neur 1950:83:437-9.

24 Remy M, Contremoulins M. Le chercheurde projectiles Vol 55: L'Illustration, 1897:423.

25 Spiegel EA, Wycis HT, Marks M, et al. Stereotaxic apparatus for operations on the human brain. Science 1947:106:349-50.

26 Spiegel EA, Wycis HT. Pallidothalamotomy in chorea. Arch Neurol Psychiatry 1950;64:295-6.

27 Spiegel EA, Wycis HT. Long range results of pallidoansotomy in paralysis agitans and parkinsonism. In: Fields WS, ed. Pathogenesis and Treatment of Parkinsonism. Springfield: Charles C Thomas, 1958:294-8.

28 Cooper IS. Ligation of the anterior choroidal artery for involuntary movements; parkinsonism. Psychiatr Q 1953:27:317-9.

29 Guiot G, Brion S. Traitment des mouvements anormaux par la coagulation pallidale: technique et resultats. Rev Neur 1953;89:578-80.

30 Bravo G, Cooper IS. Chemopallidectomy; two recent technical additions. J Am Geriatr Soc 1957:5:651-5.

31 Narabayashi H, Okuma T. Procaine oil blocking of the globus pallidus for treatment of rigidity and tremor of parkinsonism. Proc Jpn Acad 1953;29:134.

32 Cooper IS, Bravo G. Chemopallidectomy and chemothalamectomy. J Neurosurg 1958; 15:244-50.

33 Spiegel EA. Development of stereoencephalotomy for extrapyramidal diseases. J Neurosurg 1966;24:433-9.

34 Spiegel EA, Wycis HT. Pallido-ansotomy: Anatomic-physiological foundation and histopathologic control. In: Fields WS, ed. Pathogenesis and treatment of parkinsonism. Springfield: Charles C Thomas, 1958:86-105.

35 Svennilson E, Torvik A, Lowe R, et al. Treatment of parkinsonism by stereotatic thermolesions in the pallidal region. A clinical evaluation of 81 cases. Acta Psychiatr Scand 1960:35:358-77.

36 Laitinen LV, Bergenheim AT, Hariz MI. Leksell's posteroventral pallidotomy in the treatment of Parkinson's disease. J Neurosurg 1992;76:53-61.

37 Gillingham FJ, Kalyanaraman S, Donaldson AA. Bilateral stereotaxic lesions in the management of parkinsonism and the dyskinesias. Br Med J 1964:2:656-9.

38 Krauss JK. History of Sterotactic surgery in Germany. In: Lozano AM, Gildenberg PL, Tasker RR, eds. Textbook of sterotactic and functional Neurosurgery, 2009:53-8.

39 Hassler R, Riechert T. Indications and localization of stereotactic brain operations. Nervenarzt 1954:25:441-7.

40 Mundinger F, Riechert T. Indikationen und Langzeitergebnisse von 1400 uni- und bilateralen stereotaktischen Eingriffen beim Parkinsonsyndrom. Wien Zschr Nervenhk 1966:23:147-77.

41 Mundinger F, Riechert T, Disselhoff J. Long term results of stereotaxic operations on extrapyramidal hyperkinesia (excluding parkinsonism). Confin Neurol 1970;32:71-8.

42 Waltz JM, Aristizabal G, Riklan M, et al. Results of cryothalamectomy for parkinsonism in patients over 70. J Am Geriatr Soc 1967:15:1-8.

43 Spiegel EA, Wycis HT. Ansotomy in paralysis agitans. AMA Arch Neurol Psychiatry 1953:69:652-3

44 Spiegel EA, Wycis HT, SZEKELY EG, et al. Campotomy in various extrapyramidal disorders. J Neurosurg 1963:20:871-84.

45 Andy OJ, Jurko MF, Sias FR. Subthalamotomy in treatment of Parkinsonian tremor. J Neurosurg 1963;20:860-70

46 Mundinger F. Results of 500 subthalamotomies in the region of the zona incerta. In: LE S, ed. Third symposium on Parkinsons disease, 1969:261-5. 
47 Velasco FC, Molina-Negro P, Bertrand C, et al. Further definition of the subthalamic target for arrest of tremor. J Neurosurg 1972;36:184-91.

48 Hullay J, Velok J, Gombi R, et al. Subthalamotomy in Parkinson's disease. Confin Neurol 1970;32:345-8.

49 Cotzias GC, Van Woert MH, Schiffer LM. Aromatic amino acids and modification of parkinsonism. N Engl J Med 1967;276:374-9.

50 Guridi J, Lozano AM. A brief history of pallidotomy. Neurosurgery 1997;41:1169-83. Discussion1180-3.

51 Nagaseki Y, Shibazaki T, Hirai T, et al. Long-term follow-up results of selective VIMthalamotomy. J Neurosurg 1986;65:296-302.

52 Hirai T, Miyazaki M, Nakajima H, et al. The correlation between tremor characteristics and the predicted volume of effective lesions in stereotaxic nucleus ventralis intermedius thalamotomy. Brain 1983;106:1001-18.

53 Aziz TZ, Peggs D, Sambrook MA, et al. Lesion of the subthalamic nucleus for the alleviation of 1-methyl-4-phenyl-1,2,3,6-tetrahydropyridine (MPTP)-induced parkinsonism in the primate. Mov Disord 1991;6:288-92.

54 Bergman $\mathrm{H}$, Wichmann T, DeLong MR. Reversal of experimental parkinsonism by lesions of the subthalamic nucleus. Science 1990;249:1436-8.

55 Alvarez L, Macias R, Lopez G, et al. Bilateral subthalamotomy in Parkinson's disease: initial and long-term response. Brain 2005;128:570-83.

56 Guridi J, Herrero MT, Luquin MR, et al. Subthalamotomy in parkinsonian monkeys. Behavioural and biochemical analysis. Brain 1996;119:1717-27.

57 Limousin P, Pollak P, Benazzouz A, et al. Effect of parkinsonian signs and symptoms of bilateral subthalamic nucleus stimulation. Lancet 1995:345:91-5.

58 Alvarez L, Macias R, Guridi J, et al. Dorsal subthalamotomy for Parkinson's disease. Mov Disord 2001:16:72-8

59 Patel NK, Heywood P, O'Sullivan K, et al. Unilateral subthalamotomy in the treatment of Parkinson's disease. Brain 2003:126:1136-45.

60 Su PC, Tseng HM, Liu HM, et al. Treatment of advanced Parkinson's disease by subthalamotomy: one-year results. Mov Disord 2003;18:531-8.

61 Parkin S, Nandi D, Giladi N, et al. Lesioning the subthalamic nucleus in the treatment of Parkinson's disease. Stereotact Funct Neurosurg 2001;77:68-72.

62 Vilela Filho O, Silva DJ, Souza HA, et al. Stereotactic subthalamic nucleus lesioning for the treatment of Parkinson's disease. Stereotact Funct Neurosurg 2001:77:79-86.

63 Tseng HM, Su PC, Liu HM, et al. Bilateral subthalamotomy for advanced Parkinson disease. Surg Neurol 2007;68:S43-S50. Discussion S50-1.

64 Benabid AL, Pollak P, Gervason C, et al. Long-term suppression of tremor by chronic stimulation of the ventral intermediate thalamic nucleus. Lancet 1991;337:403-6.

65 Chang WS, Jung HH, Kweon EJ, et al. Unilateral magnetic resonance guided focused ultrasound thalamotomy for essential tremor: practices and clinicoradiological outcomes. J Neurol Neurosurg Psychiatry 2015;86:257-64.

66 Witjas T, Carron R, Krack P, et al. A prospective single-blind study of gamma knife thalamotomy for tremor. Neurology 2015;85:1562-8.

67 Elias WJ, Huss D, Voss T, et al. A pilot study of focused ultrasound thalamotomy for essential tremor. N Engl J Med 2013:369:640-8.

68 Lipsman N, Schwartz ML, Huang Y, et al. MR-guided focused ultrasound thalamotomy for essential tremor: a proof-of-concept study. Lancet Neurol 2013;12:462-8.

69 Elias WJ, Lipsman N, Ondo WG, et al. A randomized trial of focused ultrasound thalamotomy for essential tremor. N Engl J Med 2016;375:730-9.

70 Jourdain VA, Schechtmann G. Health economics and surgical treatment for Parkinson's disease in a world perspective: results from an international survey. Stereotact Funct Neurosurg 2014;92:71-9.

71 Organ LW. Electrophysiologic principles of radiofrequency lesion making. App/ Neurophysiol 1976;39:69-76.

72 Giller CA, Dewey RB, Ginsburg Ml, et al. Stereotactic pallidotomy and thalamotomy using individual variations of anatomic landmarks for localization. Neurosurgery 1998:42:56-65.

73 Pahwa R, Lyons KE, Wilkinson SB, et al. Comparison of thalamotomy to deep brain stimulation of the thalamus in essential tremor. Mov Disord 2001:16:140-3.

74 Leksell L, Radiosurgery C I. Gammathalamotomy in two cases of intractable pain. Acta Chir Scand 1968;134:585-95.

75 Higuchi Y, Matsuda S, Serizawa T. Gamma knife radiosurgery in movement disorders: Indications and limitations. Mov Disord 2017;32:28-35.

76 Niranjan A, Kondziolka D, Baser S, et al. Functional outcomes after gamma knife thalamotomy for essential tremor and MS-related tremor. Neurology 2000;55:443-6.

77 Ohye C, Shibazaki T, Ishihara J, et al. Evaluation of gamma thalamotomy for parkinsonian and other tremors: survival of neurons adjacent to the thalamic lesion after gamma thalamotomy. J Neurosurg 2000;93:120-7.

78 Pan L, Dai JZ, Wang BJ, et al. Stereotactic Gamma thalamotomy for the treatment of parkinsonism. Stereotact Funct Neurosurg 1996;66:329-32.

79 Martin E, Jeanmonod D, Morel A, et al. High-intensity focused ultrasound for noninvasive functional neurosurgery. Ann Neurol 2009;66:858-61.

80 Gallay MN, Moser D, Rossi F, et al. Incisionless transcranial MR-guided focused ultrasound in essential tremor: cerebellothalamic tractotomy. J Ther Ultrasound 2016;4:5.
81 Chang WS, Jung $\mathrm{HH}$, Zadicario $\mathrm{E}$, et al. Factors associated with successful magnetic resonance-guided focused ultrasound treatment: efficiency of acoustic energy delivery through the skull. J Neurosurg 2016;124:411-6.

82 Tomlinson FH, Jack CR, Kelly PJ. Sequential magnetic resonance imaging following stereotactic radiofrequency ventralis lateralis thalamotomy. J Neurosurg 1991;74:579-84.

83 Quiñones-Molina R, Molina H, Ohye C, et al. CT-oriented microrecording guided selective thalamotomy. Stereotact Funct Neurosurg 1994:62:200-3.

84 Krauss JK, Mohadjer M, Nobbe F, et al. The treatment of posttraumatic tremor by stereotactic surgery. Symptomatic and functional outcome in a series of 35 patients. J Neurosurg 1994;80:810-9.

85 Johansson F, Malm J, Nordh E, et al. Usefulness of pallidotomy in advanced Parkinson's disease. J Neurol Neurosurg Psychiatry 1997:62:125-32.

86 Eskandar EN, Shinobu LA, Penney JB, et al. Stereotactic pallidotomy performed without using microelectrode guidance in patients with Parkinson's disease: surgical technique and 2-year results. J Neurosurg 2000;92:375-83.

87 Atkinson JD, Collins DL, Bertrand G, et al. Optimal location of thalamotomy lesions for tremor associated with Parkinson disease: a probabilistic analysis based on postoperative magnetic resonance imaging and an integrated digital atlas. $J$ Neurosurg 2002;96:854-66.

88 Hariz Ml, Hirabayashi H. Is there a relationship between size and site of the stereotactic lesion and symptomatic results of pallidotomy and thalamotomy? Stereotact Funct Neurosurg 1997;69:28-45.

89 Goodman SH, Wilkinson S, Overman J, et al. Lesion volume and clinical outcome in stereotactic pallidotomy and thalamotomy. Stereotact Funct Neurosurg 1998;71:164-72.

90 Elias WJ, Khaled M, Hilliard JD, et al. A magnetic resonance imaging, histological, and dose modeling comparison of focused ultrasound, radiofrequency, and Gamma Knife radiosurgery lesions in swine thalamus. J Neurosurg 2013;119:307-17.

91 Krauss JK, Desaloms JM, Lai EC, et al. Microelectrode-guided posteroventral pallidotomy for treatment of Parkinson's disease: postoperative magnetic resonance imaging analysis. J Neurosurg 1997;87:358-67.

92 Wintermark M, Druzgal J, Huss DS, et al. Imaging findings in MR imaging-guided focused ultrasound treatment for patients with essential tremor. AJNR Am J Neuroradiol 2014;35:891-6.

93 Schreglmann SR, Bauer R, Hägele-Link S, et al. Unilateral cerebellothalamic tract ablation in essential tremor by MRI-guided focused ultrasound. Neurology 2017:88:1329-33

94 Friehs GM, Ojakangas CL, Pachatz P, et al. Thalamotomy and caudatotomy with the Gamma Knife as a treatment for parkinsonism with a comment on lesion sizes. Stereotact Funct Neurosurg 1995;64:209-21.

95 Ohye C, Higuchi Y, Shibazaki T, et al. Gamma knife thalamotomy for Parkinson disease and essential tremor: a prospective multicenter study. Neurosurgery 2012;70:526-35

96 Ohye C, Shibazaki T, Sato S. Gamma knife thalamotomy for movement disorders: evaluation of the thalamic lesion and clinical results. J Neurosurg 2005;102:234-40.

97 Young RF, Li F, Vermeulen S, et al. Gamma Knife thalamotomy for treatment of essential tremor: long-term results. J Neurosurg 2010;112:1311-7.

98 Young RF, Jacques S, Mark R, et al. Gamma knife thalamotomy for treatment of tremor: long-term results. J Neurosurg 2000;93:128-35.

99 Kondziolka D, Ong JG, Lee JY, et al. Gamma Knife thalamotomy for essential tremor. J Neurosurg 2008;108:111-7.

100 Lim SY, Hodaie M, Fallis M, et al. Gamma knife thalamotomy for disabling tremor: a blinded evaluation. Arch Neurol 2010:67:584-8.

101 Schreglmann SR, Krauss JK, Chang JW, et al. Functional lesional neurosurgery for tremor-a protocol for a systematic review and meta-analysis. BMJ Open 2017;7:e015409.

102 Schreglmann SR, Kägi G. Functional lesional neurosurgery for tremor: back to the future? Journal of Neurology, Neurosurgery, and Psychiatry. In Press. 2017.

103 Hariz M. Focused ultrasound thalamotomy improves essential tremor. Mov Disord 2013;28:28.

104 Ravikumar VK, Parker JJ, Hornbeck TS, et al. Cost-effectiveness of focused ultrasound, radiosurgery, and DBS for essential tremor. Mov Disord 2017:32:1165-73.

105 Esselink RA, de Bie RM, de Haan RJ, et al. Unilateral pallidotomy versus bilateral subthalamic nucleus stimulation in PD: a randomized trial. Neurology 2004:62:201-7.

106 Mann JM, Foote KD, Garvan CW, et al. Brain penetration effects of microelectrodes and DBS leads in STN or GPi. J Neurol Neurosurg Psychiatry 2009:80:794-8.

107 Mestre TA, Lang AE, Okun MS. Factors influencing the outcome of deep brain stimulation: placebo, nocebo, lessebo, and lesion effects. Mov Disord 2016:31:290-8.

108 Jankovic J, Cardoso F, Grossman RG, et al. Outcome after stereotactic thalamotomy for parkinsonian, essential, and other types of tremor. Neurosurgery 1995;37:680-7.

109 Merello M, Tenca E, Pérez Lloret S, et al. Prospective randomized 1-year follow-up comparison of bilateral subthalamotomy versus bilateral subthalamic stimulation and the combination of both in Parkinson's disease patients: a pilot study. $\mathrm{Br} J$ Neurosurg 2008;22:415-22. 
110 Shima F, Ishido K, Sun SJ, et al. Surgical control of akinesia in Parkinson's disease. Eur Neurol 1996:36:55-61.

111 Zirh A, Reich SG, Dougherty PM, et al. Stereotactic thalamotomy in the treatment of essential tremor of the upper extremity: reassessment including a blinded measure of outcome. J Neurol Neurosurg Psychiatry 1999;66:772-5.

112 Blomstedt P, Sandvik U, Fytagoridis A, et al. The posterior subthalamic area in the treatment of movement disorders: past, present, and future. Neurosurgery 2009:64:1029-38.

113 Murata J, Kitagawa M, Uesugi H, et al. Electrical stimulation of the posterior subthalamic area for the treatment of intractable proximal tremor. J Neurosurg 2003;99:708-15.
114 Plaha P, Patel NK, Gill SS. Stimulation of the subthalamic region for essential tremor. J Neurosurg 2004;101:48-54

115 Herzog J, Hamel W, Wenzelburger R, et al. Kinematic analysis of thalamic versus subthalamic neurostimulation in postural and intention tremor. Brain 2007; 130:1608-25

116 Groppa S, Herzog J, Falk D, et al. Physiological and anatomical decomposition of subthalamic neurostimulation effects in essential tremor. Brain 2014;137:109-21.

117 Sandvik U, Koskinen LO, Lundquist A, et al. Thalamic and subthalamic deep brain stimulation for essential tremor: where is the optimal target? Neurosurgery 2012;70:840-5. 